\title{
Application of Weighted Product Method for Determining Home Renovation Assistance in Pringsewu District
}

\author{
Muhamad Muslihudin, B. Ayshwarya, Effendi, Desi Yusfika, Muhammad Rizky Pribadi, Ferry Susanto, \\ Wahidah Hashim, Phong Thanh Nguyen, Andino Maseleno, Siti Mukodimah, Diny Vellyana
}

\begin{abstract}
House is a place that is needed by human beside clothing and food. House has important function for all people, a place to unwind and gather with family. A good and comfortable house condition will make family harmony, therefore Pringsewu district government conducts a home renovation assistance program for underprivileged in Pringsewu District. The obstacles faced by local government in implementing home renovation assistance are to determine which citizens are eligible for home renovation assistance. This problem can be overcome by creating an effective and efficient home renovation assistance assessment system. By using the method of weighted product it is expected to help the performance of the local government in Pringsewu District, the method of weighted product was selected because it is able to select alternatives from each alternative. The function of this method is to determine the weight scoew for each alternative and the criteria that have been determined. There are six criteria used in this study, namely: (1) House Wall, (2) Roof Structure (3) Residential Floor (4) Latrine condition (5) Occupation of Head of Household (6) Certificate of House Ownership. In addition the criteria also used criteria weighting score to determine the alternative obtained. The smallest score was in V3 with score of 0.122124 and alternative A3was the alternative selected as the recipient of home renovation assistance in Pringsewu district.
\end{abstract}

Index Terms: Weighted Product, Pringsewu, Home Renovation

\section{INTRODUCTION}

\section{Background}

Every human being wherever they are, needs a place to live which can be called house. The house has very important function for all people, a place to unwind and gather with family, and as a shelter for human.

Revised Manuscript Received on June 22, 2019.

Muhamad Muslihudin, STMIK Pringsewu, Lampung, Indonesia

B. Ayshwarya, Department of Computer Science, Kristu Jayanti College, Bangalore-560043, India.

Effendi, STKIP Nurul Huda Sukaraja, South Sumatera, Indonesia

Desi Yusfika, STMIK Pringsewu, Lampung, Indonesia

Muhammad Rizky Pribadi, STMIK MDP Palembang, South

Sumatera, Indonesia

Ferry Susanto, STMIK Surya Intan, North Lampung, Indonesia

Phong Thanh Nguyen, Department of Project Management, Ho Chi Minh City Open University (HCMCOU), Vietnam.

Wahidah Hashim, Institute of Informatics and Computing Energy, Universiti Tenaga Nasional, Malaysia

Andino Maseleno, Institute of Informatics and Computing Energy, Universiti Tenaga Nasional, Malaysia

Siti Mukodimah, STMIK Pringsewu, Lampung, Indonesia

Diny Vellyana, STIKES Muhammadiyah Pringsewu, Pringsewu, Lampung, Indonesia
Therefore, the Pringsewu District Government conducted a home renovation program for the underprivileged in Pringsewu District. Poverty makes a person unable to complete the basic needs of himself and his family which includes physical, mental and social needsWith the non-fulfillment of basic human needs it will have implication for neglect of family member and social disability.

Based on Constitution of 1945, CHAPTER XA's 1945 , Article $28 \mathrm{H}$ about Human Right, it explained that a proper place to live and the environment is the right of everyone. Because everyone has the right to live physically and mentally, live, and get a good and healthy environment [1].

According to research conducted by Dodi Kuswandi (2017), it explains that the results of this experiment use alternative data as many as 15 and 5 criteria, the ranking of data generated by recipients of uninhabitable home renovation with the highest priority of the sequence shows the most appropriate renovation assistance to the most eligible until the least eligible for the citizen [2].

According to journal written by Yosa'arozai (2017) about the role of decision support system in the overall context of the information system aimed to improve performance through application of information technology and determining the approach used in the decision-making process to evaluate interactive selection [3].

In general, houses that can get house assistance must include the following criteria: (1) land area (2) age (3) family household occupation (4) last education. In this study the author tries to apply the WP method (weighted produtct ) to determine the assessment of home renovation assitance recipient in Pringsewu District, because this method gives weighting to each criterion and then is carried out ranking process to get a decision on who is eligible for home renovation assistance in Pringsewu District. The process of calculating the WP method (weighted produtct) is static so that it cannot be changed if there is a change in criteria. [4]

By applying the WP method (weighted produtct) to the assessment of home renovation assesment, a method of selecting the best home renovation will be obtained as a standard for home renovation in Pringsewu District.

\section{Formulation of Problem}

According to above background, the formulation of the research problem that was taken was how to determine the home renovation study in Pringsewu District by using the WP method (weighted produtct). 
How to obtain criteria or variable assessment of the home renovation recipient in Pringsewu District.

\section{Decision Support Systems}

\section{THEORY}

According to Michale S. Scott-Morton, (1970), it was first articulated an important concept of decision support system (DSS)). He defined DSS as an interactive computer-based system, which helps decision makers to use data and various models to solve related problems [5][1][2].

According to Turban, E., Jay E., Aranson and Liang (2007), decision support system as systems that is used as a problem-solving tool to help decision makers (managers) in determining decision but not to replace the capacity of manager, it just only gives consideration. DSS is intended for decisions that require assessment or decisions that cannot be supported by the algorithm [6][3][4], [5].

According to Kusrini, (2007, p. 15) Decision support system is an interactive information system that provides information, modeling, and data manipulation . This system is used to assist decision making in semi-structured situation and unstructured situation, where one does not know exactly how the decision should be made (Alter, 2002)[7]. The objectives of the decision support system are: (Turban, 2005): [7][2]

1. To help manager in making decision or semi-structured issues.

2. To provide support for manager's attention and not intended to replace manager's functions.

3. To increase the effectiveness of decisions taken by managers more than improving their efficiency.

4. To allow decision maker to do computation quickly with low costs.

5. To Increase productivity.

6. Quality support

7. Competitiveness

8. To overcome cognitive limitations in processing and storage.

\section{Fuzzy Multi Attribute Decision Making}

According to the journal written by Nurul Fitriani and Sri Ipnuwati Fuzy Multiplier Attribute Decision is a further development of MADM[6][6], [7], Basically MADM process is carried out through three stages, namely the preparation of the components of the situation, analysis and synthesis of information. There are several methods that can be used to solve FMADM problems, namely [8][8], [9]. : [8], Simple Additive Weighting Method (SAW), Weighted Product (WP), Elimination et choix traduisant la realite (ELECTRE), Technique for Order Preference ny Similarity to Ideal Solution (TOPSIS), Analityc Hierarchy Process (AHP)[3], [5], [10]-[12]

\section{Definition of House}

According to (Santoso, 2002: 39), House is the main refuge for human from the climate, then also from other physical disorder. House is a basis for maintaining production capability, a place to rest, a place to maintain health, as well as a place to study and prepare themselves [9].

\section{Characteristics of Home renovation Assistance Recipient}

Characteristics of families who are eligible for house assistance recipient include:

a. Have valid ID / identity b. Registered as a poor family

c. Income below Regional Minimum Wage (UMR)

d. Everyday life still needs help to support his family

e. Own private land

f. The dwelling that is owned and occupied is unhabitable residence [9].

\section{Criteria for prospective home renovation admission}

Criteria of houses that are eligible for home renovation assistance in this study are measured using indicators [9]:

1. House wall

2. Roof structure

3. Residence floor

4. WC / latrine condition

5. The head of household occpupation

6. Certificate of land ownership

\section{RESEARCH METHOD}

\section{Stages of Data Collection}

\section{Observai method}

At this observation stage the researcher made a direct observation about the condition of the house Pringsewu District Area, then continued with the assessment process of the house that was made as objects of research. From the results of these observation, researchers found several houses from house alternatives that have been determined, it can be categorized as healthy houses, by comparing the score of each alternative.

\section{Interview Method}

In this stage the researcher took an approach to the community, especially the resident of the house who be the object of research to obtain a data or information needed, it can help determine the home renovation research according to predetermined criteria, namely by interviewing the results obtained, it will be compared with the results of the score of other alternative.

\section{Library Method}

In this stage, the author also used the library method or literature as a reference from known research journals. In this case the author looked for, learnt, and summarized various kinds of literature or journal references related to research problems.

\section{WP Method (Weighted Product)}

The weighted product method required a normalization process because this method multiplied the results of the assessment of each attribute. The multiplication results had not been meaningful if they had not been compared (divided) with standard score. The weight for benefit attributes served as a positive rank in The multiplication process, while the cost weight functioned as a negative rank. The weighted product method used multiplication to link the attribute rating, where the rating of each attribute must be obtained first with the corresponding weight. This process was the same as the normalization process [10][13], [14]. 
According to Yoon (Kusumadewi, 2006), the WP method used multiplication technique to link attribute ratings, where the rating of each attribute must be squared first by the weight of the attribute in question.

The stages in using the wp method (weighted product) are determining the criteria that will be used as a reference in decision making [10].

1. determine the suitability rating of each alternative on each criterion. (Matrix X)

2. determine the weight of preference for each criterion. (Matrix W)

3. multiply all attributes for an alternative with a weight as a positive rank for the attribute of profit and a negative rank weight for the attribute of the cost. (Matrix S)

4. The multiplication results are summed to generate $\mathrm{V}$ score for each alternative. (Matrix V)

5. Look for alternative score by performing the same step as in step one, just use the highest score for each of the highest attributes for each benefit attribute and the lowest score for the cost attribute.

6. Divide the score of $\mathrm{V}$ for each alternative with a standard score (V $(\mathrm{A} *)$ ) that produces $\mathrm{R}$.

7. Look for ideal alternative score.

Formulated as follows:

$A=\prod_{A=1}^{n}(X i j)^{w j}$

Where :

$\mathrm{S}=$ state alternative preferences that is analogous to vector $\mathrm{S}$

$\mathrm{X}=$ state the score criteria

$\mathrm{W}=$ state the weight criteria

$\mathrm{I}=$ state alternative

$\mathrm{J}=$ state criteria

$\mathrm{N}=$ state the number of criteria

$\Sigma \mathrm{Wj}=1$

$\mathrm{Wj}$ is a positive score for profit attribute, and negative score for cost attribute. The relative preferences of each alternative are given as follows:

$A=\frac{\Pi_{j}^{\mathrm{n}}=1\left(x_{i j}\right)^{w j}}{\Pi_{j}^{\mathrm{n}}=1\left(x_{i}\right)^{\mathrm{wj}}}$

Where :

$\mathrm{V}=$ state that alternative preference that is analogous to $\mathrm{V}$ vector

$\mathrm{X}=$ state the score criteria

$\mathrm{W}=$ state the weight criteria

$\mathrm{i}=$ state alternative

$\mathrm{j}=$ state criteria

$\mathrm{n}=$ state the number of criteria

$*=$ state the number of criteria which has been assessed on $\mathrm{S}$.

\section{vector}

In this study there were weight and criteria in determining the assessment of home surgery in the Pringsewu District, the criteria are as follows:

Table. 1 Criteria table

\begin{tabular}{|c|l|c|}
\hline Criteria & \multicolumn{1}{|c|}{ Description } & Score \\
\hline C1 & The Wall & 25 \\
\hline C2 & Roof structure & 15 \\
\hline
\end{tabular}

\begin{tabular}{|c|l|c|}
\hline C3 & Residence floor & 10 \\
\hline C4 & Laterine condition & 20 \\
\hline C5 & $\begin{array}{l}\text { Head of household } \\
\text { occupation }\end{array}$ & 15 \\
\hline C6 & $\begin{array}{l}\text { Certificate of home } \\
\text { ownership }\end{array}$ & 15 \\
\hline
\end{tabular}

Alternative:

A1: House 1

A2: House 2

A3: House 3

A4: House 4

A5: House 5

\section{Research Framework}

Research framework is how to determine the criteria for the recipient of home renovation assistance in Pringsewu district using weighted product (WP) method. This method was carried out by identifying a problem, collecting data through observation, interviews, and conducting library research [13-48]. The system design used was as follows: Stage I The user must first identify the problem, then proceed with formulating the problem and then determining the title. Step II After determining the title then decide whether the problem is worth to be observed or not. Stage III If not, it will be identified again. Stage IV If Yes, then it will be continued by collecting data. Stage V After that the data were inputted to run the system, the data include: data criteria, attribute, and data weight for resident who was eligible for home renovation assistance. Stage VI After the input data, the system will make weight improvement. Stage VII After that the system perform preference by multiplying all attributes (criteria) for all alternatives by weighting as a positive rank for the attributes of profit and negative as a cost. Stage VIII After the score was obtained, then it was sorted from the highest to the lowest, and the lowest score was chosen as a citizen who deserves home surgery assistance. Stage IV the criteria of house system output along with the preference scores that had been sorted from the lowest to the highest. 


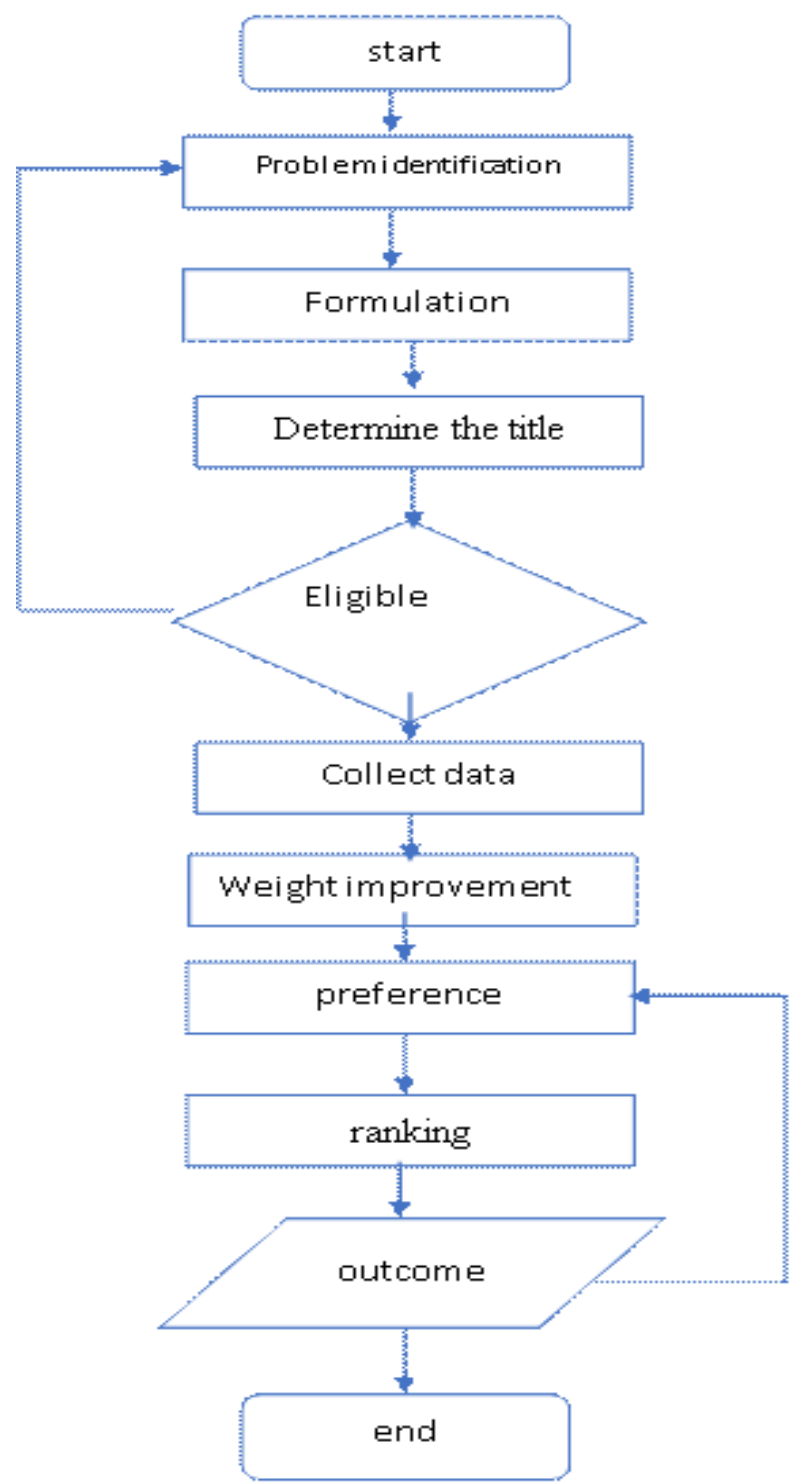

Fig. 1 Research framework

\section{DISCUSSION}

\section{Research Results}

In this study there were weights and criteria in the assessment of home surgical assistance in pringsewu district. Below is a table of the criteria that had been specified as follows :

Table. 2 Table of Criteria

\begin{tabular}{|l|l|l|}
\hline Criteria & Description & Score \\
\hline C1 & The Wall & 25 \\
\hline C2 & Roof structure & 15 \\
\hline C3 & Residence floor & 10 \\
\hline C4 & Laterine condition & 20 \\
\hline C5 & $\begin{array}{l}\text { Head of household } \\
\text { occupation }\end{array}$ & 15 \\
\hline C6 & $\begin{array}{l}\text { Certificate of } \\
\text { home ownership }\end{array}$ & 15 \\
\hline & A Total of & 100 \\
\hline
\end{tabular}

Table. 3 Description of the score weight

\begin{tabular}{|c|c|}
\hline Weight & Score \\
\hline Very bad & 1 \\
\hline bad & 2 \\
\hline pretty good & 3 \\
\hline good & 4 \\
\hline Very good & 5 \\
\hline
\end{tabular}

Table. 4 C1 (home wall table)

\begin{tabular}{|c|c|c|}
\hline $\begin{array}{c}\text { The criteria for } \\
\text { the wall of the } \\
\text { house }\end{array}$ & weight & score \\
\hline Bamboo & Very bad & 1 \\
\hline plywood & Bad & 2 \\
\hline board & Pretty good & 3 \\
\hline wall & Very good & 5 \\
\hline
\end{tabular}

Table. 5 C2 (roof structure table)

\begin{tabular}{|c|c|c|}
\hline $\begin{array}{c}\text { Criteria of the } \\
\text { roof }\end{array}$ & weight & score \\
\hline Straw & Very bad & 1 \\
\hline Asbestos zinc & bad & 2 \\
\hline Tile & Very good & 5 \\
\hline
\end{tabular}

Table. 6 C3 (floor residence)

\begin{tabular}{|c|c|c|}
\hline Criteria & weight & score \\
\hline ceramics & Very good & 5 \\
\hline soil & bad & 2 \\
\hline cement & good & 4 \\
\hline
\end{tabular}

Table. 7 C4 (condition of laterine table)

\begin{tabular}{|c|c|c|}
\hline Criteria & weight & score \\
\hline toilet & Very good & 5 \\
\hline pool & Bad & 2 \\
\hline River & Very bad & 1 \\
\hline
\end{tabular}

Table. 8 C5 (The head of household occupation)

\begin{tabular}{|c|c|c|}
\hline Criteria & weight & score \\
\hline employee & Very good & 5 \\
\hline famers & Pretty good & 3 \\
\hline retired & good & 4 \\
\hline unemployment & Very bad & 1 \\
\hline
\end{tabular}

Table. 9 C6 ( land ownership)

\begin{tabular}{|c|c|c|}
\hline $\begin{array}{c}\text { Criteria } \\
\text { certificate }\end{array}$ & weight & score \\
\hline there is & Very good & 5 \\
\hline In pledge & bad & 2 \\
\hline Not have & Very bad & 1 \\
\hline
\end{tabular}

Published By:

Blue Eyes Intelligence Engineering \& Sciences Publication 
Table. 10 Alternative table

\begin{tabular}{|c|c|}
\hline Alternative & House \\
\hline A1 & House 1 \\
\hline A2 & House 2 \\
\hline A3 & House 3 \\
\hline A4 & House 4 \\
\hline A5 & House 5 \\
\hline
\end{tabular}

After knowing the house data that will be assessed, it gives weight to each criterion based on the data obtained in each house. .

Table. 11 Alternative weighting for each criterion

\begin{tabular}{|c|c|c|c|c|c|c|}
\hline & C1 & C2 & C3 & C4 & C5 & C6 \\
\hline A1 & 3 & 4 & 2 & 5 & 4 & 5 \\
\hline A2 & 2 & 4 & 5 & 2 & 3 & 5 \\
\hline A3 & 1 & 1 & 2 & 1 & 3 & 5 \\
\hline A4 & 3 & 4 & 4 & 1 & 3 & 5 \\
\hline A5 & 1 & 2 & 2 & 2 & 3 & 5 \\
\hline
\end{tabular}

\section{Calculation}

Before calculating, determine the initial weight of each criterion, while the initial weight of each criterion was $\mathrm{W}=$ $(25,15,15,10,20,15)$, it will be corrected so that the total weight $\sum w j:, 2$ by:

a. the score of $\mathrm{W}$

$w j=\frac{w j}{\sum w j}$

$$
\begin{gathered}
w_{1}=\frac{25}{25+15+15+10+20}=\frac{25}{100}=0,25 \\
w_{2}=\frac{15}{25+15+15+10+20}=\frac{15}{100}=0,15 \\
w_{2}=\frac{10}{25+15+\frac{15}{20}+10+20}=\frac{10}{100}=0,1 \\
w_{4}=\frac{\frac{20}{25}}{25+15+15+10+20}=\frac{15}{100}=0,2 \\
w_{5}=\frac{\frac{15}{25+15+15+10+20}=\frac{15}{100}=0,15}{w_{6}}=\frac{15}{25+15+15+10+20}=\frac{15}{100}=0,15
\end{gathered}
$$

b. Calculating $\mathrm{S}$ vector in the following ways:

$$
S i=\prod_{j}^{n} x_{i j}{ }^{v j}
$$

Where $\sum \llbracket w j=1 \rrbracket . w j$ was a positive score for the gain attribute and had a negative score for the bj attribute. This calculation was done by multiplying all attributes (criteria) for all alternatives with $\mathrm{W}$ (weight) as a positive rank for attributes of profit and negative as a cost. The calculation method is as follows:

$$
\begin{aligned}
& S_{1}=\left(3^{0.25}\right)\left(4^{0.15}\right)\left(2^{0,1}\right)\left(5^{0,2}\right)\left(4^{0,15}\right)\left(5^{0,15}\right)=3.755267 \\
& S_{2}=\left(2^{0,25}\right)\left(4^{0,15}\right)\left(5^{0,1}\right)\left(2^{0,2}\right)\left(3^{0,15}\right)\left(5^{0,15}\right)=2.965399 \\
& S_{3}=\left(1^{0,25}\right)\left(1^{0,15}\right)\left(2^{0,1}\right)\left(1^{0,2}\right)\left(3^{0,15}\right)\left(5^{0,15}\right)=1.608854 \\
& S_{4}=\left(3^{0,25}\right)\left(4^{0,15}\right)\left(4^{0,1}\right)\left(1^{02}\right)\left(3^{0,15}\right)\left(5^{0,15}\right)=2.793888 \\
& S_{5}=\left(1^{0,25}\right)\left(2^{0,15}\right)\left(2^{0,1}\right)\left(2^{0,2}\right)\left(3^{0,15}\right)\left(5^{0,15}\right)=2.050582
\end{aligned}
$$

After getting $\mathrm{S}$ vector score, then determine the ranking:

$$
\mathrm{V}_{\mathrm{i}}=\frac{\prod_{j=1}^{M} x_{i j} v_{j j}}{\prod_{j=1}^{M}\left(x_{j}^{v}\right) w j j}
$$

By dividing the score of $\mathrm{A}$ (the score of the vector used for ranking) for each alternative by means of the total score of each alternative (vector $\mathrm{S}$ ).

$V_{1}=\frac{3.755267}{13.17399}=0.285052$

$\mathrm{V}_{2}=\frac{2.965399}{13.17399}=0.225095$

$V_{\mathrm{a}}=\frac{1.608854}{13.17399}=0.122124$

$V_{4}=\frac{2.793888}{13.17399}=0.212076$

$V_{5}=\frac{2.050582}{13.17399}=0.155654$

\section{Results}

After calculating the score of vector $\mathrm{V}$, the smallest score that becomes an alternative is worthy of getting home surgery assistance.

Table. 12 Results of Pringsewu residents who were eligible for home surgery assistance

\begin{tabular}{|l|l|l|}
\hline No & Alternative & Outcome \\
\hline 1 & House 1 & $\mathbf{0 . 2 8 5 0 5 2}$ \\
\hline 2 & House 2 & $\mathbf{0 . 2 2 5 0 9 5}$ \\
\hline 3 & House 3 & $\mathbf{0 . 1 2 2 1 2 4}$ \\
\hline 4 & House 4 & $\mathbf{0 . 2 1 2 0 7 6}$ \\
\hline 5 & House 5 & $\mathbf{0 . 1 5 5 6 5 4}$ \\
\hline
\end{tabular}

From table 11 the results of the assessment can be seen by residents who recieved a home renovation assistance, the residents of house 3 with the result of the score was $V_{-} 3=$ 0.122124

\section{Analysis of Implementation Results}

Implementation is usually used after the design has been considered fix, and in this DSS the researcher implemented through manual calculation and computerized calculations using Excel. There is a difference between manual calculation and excel. Where the manual calculation is easier because we immediately find the results. Whereas using excel must manually count first, then we enter Excel so that there is a calculation twice.

\section{CONCLUSION}

This study can be concluded that the WP method (wighted producth) can help in making decisions to determine the recipient of home renovation assistance in Pringsewu District with the criteria that researchers have determined. In this study researchers used manual calculations and used computer. With calculations using Ms. Excl makes it is easy for researchers to determine who receives home renovation assistance. 
In this study researchers only used five criteria. As for the suggestions for the researchers in the future, this research can be developed further by adding criteria, changing the criteria for weighting criteria or using other methods.

\section{REFERENCES}

1. E. Turban, R. Sharda, and D. Delen, Decision Support and Business Intelligence Systems. Chapter 6 Artificial Neural Networks for Data Mining, vol. 8th. 2007.

2. E. Turban, J. E. Aronson, and T.-P. Liang, "Decision Support Systems and Intelligent Systems," Decis. Support Syst. Intell. Syst., vol. 7, p. 867, 2007.

3. S. Kusumadewi, S. Hartati, A. Harjoko, and Retanto Wardoyo, Fuzzy Multi-Attribute Decision Making (Fuzzy MADM). Yogyakarta: Graha Ilmu, 2013.

4. A. Mardani, A. Jusoh, and E. K. Zavadskas, "Fuzzy multiple criteria decision-making techniques and applications - Two decades review

5. E. K. Zavadskas, A. Mardani, Z. Turskis, A. Jusoh, and K. M. Nor, "Development of TOPSIS Method to Solve Complicated Decision-Making Problems - An Overview on Developments from 2000 to 2015,” Int. J. Inf. Technol. Decis. Mak., vol. 15, no. 03, 2016.

6. A. Alinezhad, A. Amini, and A. Alinezhad, "Sensitivity analysis of simple additive weighting method (SAW): the results of change in the weight of one attribute on the final ranking of alternatives," J. Ind. Eng., 2009.

7. W. Waziana, R. Irviani, I. Oktaviani, F. Satria, D. Kurniawan, and A. Maseleno, "Fuzzy Simple Additive Weighting for Determination of Recipients Breeding Farm Program," vol. 118, no. 7, pp. 93-100, 2018

8. S. Mukodimah, M. Muslihudin, A. Andoyo, S. Hartati, and A. Maseleno, "Fuzzy Simple Additive Weighting and its Application to Toddler Healthy Food," Int. J. Pure Appl. Math., vol. 118, no. 7, pp. 1-7,2018.

9. M. Muslihudin, T. S. Susanti, A. Maseleno, and S. Pringsewu, "The Priority of Rural Road Development using Fuzzy Logic based Simple Additive Weighting," Int. J. Pure Appl. Math., vol. 118, no. 8, pp. 9-16, 2018.

10. T. Noviarti, M. Muslihudin, R. Irviani, and A. Maseleno, "Optimal Dengue Endemic Region Prediction using Fuzzy Simple Additive Weighting based Algorithm," Int. J. Pure Appl. Math., vol. 118, no. 7,

11. M. Muslihudin, R. Fitri Andriyanti, S. Mukodimah, P. Sistem Informasi, and S. Pringsewu Lampung, "Implementasi Metode Weighted Product Menentukan Beasiswa Bidik Misi Stmik Pringsewu," Jatisi, vol. 4, no. 2, 2018.

12. J. R. S. C. Mateo, "Weighted sum method and weighted product method," in Green Energy and Technology, 2012, vol. 83, pp. 19-22.

13. Manikandan, V., et al. "PRIVACY PRESERVING DATA MINING USING THRESHOLD BASED FUZZY CMEANS CLUSTERING." ICTACT Journal on Soft Computing 9.1 (2018).

14. Batri, K., and M. Sivaram. "Testing the impact of odd and even point crossover of genetic algorithm over the data fusion in information retrieval." European Journal of Scientific Research (2012).

15. Steffin Abraham, Tana Luciya Joji , Sivaram M, D.Yuvaraj, "Enhancing Vehicle Safety With Drowsiness Detection Andcollision Avoidance" International Journal of Pure and Applied Mathematics, 22/articles/22b/39.pdf

16. M. Sivaram, K. Batri, Amin Salih Mohammed and V. Porkodi, "Exploiting the Local Optima in Genetic Algorithm using Tabu Search", Indian Journal of Science and Technology, Vol 12(1), DOI: 10.17485/ijst/2018/v12i1/139577, January 2019.

17. Nithya, S., Sundara Vadivel, P., Yuvaraj, D., Sivaram, M. "Intelligent based IoT smart city on traffic control system using raspberry Pi and robust waste management", Journal of Advanced Research in Dynamical and Control Systems, Pages: 765-770, 2018.

18. Porkodi, V., et al. "Survey on White-Box Attacks and Solutions." Asian Journal of Computer Science and Technology 7.3 (2018): 28-32.

19. Viswanathan, M., Sivaram, M., Yuvaraj, D., Mohammed, A.S. "Security and privacy protection in cloud computing", Journal of Advanced Research in Dynamical and Control Systems, Pages 1704-1710, 2018

20. Mohammed, Amin Salih, D. Yuvaraj, M. Sivaram, and V. Porkodi. "Detection And Removal Of Black Hole Attack In Mobile Ad Hoc Networks Using Grp Protocol." International Journal of Advanced Research in Computer Science 10, no. 6 (2018). from 1994 to 2014," Expert Syst. Appl., vol. 42, no. 8, 2015. pp. 473-478, 2018. Volume 118 No. 22 2018, 921-927. https://acadpubl.eu/hub/2018-118

21. Sivaram, M., B. DurgaDevi, and J. Anne Steffi. "Steganography of two LSB bits." International Journal of Communications and Engineering 1.1 (2012): 2231-2307.

22. Dhivakar, B., et al. "Statistical Score Calculation of Information Retrieval Systems using Data Fusion Technique." Computer Science and Engineering 2.5 (2012): 43-5.

23. K. Mahalakshmi, M.Sivaram, K. Shantha Kumari, D.Yuvaraj, R.Keerthika, "Healthcare Visible Light Communication", International Journal of Pure and Applied Mathematics, Volume 118 No. 11 2018, 345-348, https://acadpubl.eu/jsi/2018-118-10-11/articles/11/41.pdf.

24. Punidha, R.,Pavithra K, Swathika R, and Sivaram M, “ Preserving DDoS Attacks sing Node Blocking Algorithm." International Journalof Pure and Applied Mathematics, Vol.119, o. 15, 2018, pp 633- 640. https://acadpubl.eu/hub/2018-119-15/3/473.pdf

25. Sivaram.M, Yuvaraj.D, Amin Salih Mohammed, Porkodi.V "Estimating the Secret Message in the Digital Image" International Journal of Computer Applications, 181(36):26-28, January 2019.

26. Punidha, R., avithra K, Swathika R, and Sivaram M, “ Preserving DDoS Attacks sing Node Blocking Algorithm.” International Journalof Pure and Applied Mathematics, Vol.119, o. 15, 2018, pp 633-640. https://acadpubl.eu/hub/2018-119-15/3/473.pdf

27. Sivaram, M., Yuvaraj, D., Porkodi, V., Manikandan, V. "Emergent news event detection from facebook using clustering" Journal of Advanced Research in Dynamical and Control Systems, Pages:1941-1947, 2018

28. Sivaram M, Batri K, “ Odd and Even Point Crossover Based Tabu GA for Data Fusion in InformationRetrieval",http://hdl.handle.net/10603/389 35, 10-Apr-2015.

29. Sivaram, M. "Odd And Even Point Crossover Based Tabu Ga For Data Fusion In Information Retrieval." (2014)

30. Malathi, N., and M.Sivaram. "An Enhanced Scheme to Pinpoint Malicious Behavior of Nodes In Manet's." (2015).

31. Mohammed, A.S., Kareem, S.W., Al Azzawi, A.K., Sivaram, M. "Time series prediction using SRE-NAR and SRE-ADALINE", Journal of Advanced Research in Dynamical and Control Systems, Pages: 1716-1726, 2018.

32. Mohammed, Sivaram Yuvaraj Amin Salih, and V. Porkodi. "Estimating the Secret Message in the Digital Image." International Journal of Computer Applications 181.36 (2019): 26-28

33. Sivaram, M., et al. "Estimating the Secret Message in the Digital Image." International Journal of Computer Applications 975: 8887.

34. Sivaram, M., et al. "The Real Problem Through a Selection Making an Algorithm that Minimizes the Computational Complexity."

35. Obulatha-II-ME-CSE, Miss O. "Position Privacy Using LocX."

36. SRE-NAR, Time Series Prediction Using. "SRE-ADALINE."

37. Kousik, N. V., M. Sivaram, and S. Kalidass. "AUTONOMOUS GREEDY ROUTING IN WIRELESS SENSOR NETWORKS."

38. S, Deepa and M, Sivaram, Enabling Anonymous Endorsement in Clouds with Decentralized Access Control (June 2015). International Journal of Scientific Engineering and Applied Science (IJSEAS) Volume-1, Issue-3, June 2015. Available at SSRN: https://ssrn.com/abstract $=3352128$

39. M, Sivaram, 4G and 5G Communication Networks Future Analysis (April 11, 2019). Available at SSRN: https://ssrn.com/abstract=

40. M, Sivaram and Sivaram, Porkodi and manikandan, V, Securing the Sensor Networks Along With Secured Routing Protocols for Data Transfer in Wireless Sensor Networks (OCTOBER 28, 2018). Available at SSRN: https://ssrn.com/abstract=

41. Sivaram, M., et al. "DETECTION OF ACCURATE FACIAL DETECTION USING HYBRID DEEP CONVOLUTIONAL RECURRENT NEURAL NETWORK." ICTACT Journal on Soft Computing 9.2 (2019).

42. R.Punidha, M.Sivaram, "Integer Wavelet Transform Based Approach For High Robustness Of Audio Signal Transmission", International Journal of Pure and Applied Mathematics, Volume 116 No. 232017 , 295-304, https://acadpubl.eu/jsi/2017-116-23-24/articles/23/40.pdf

43. Sivaram M., Mohammed A.S., Yuvaraj D., Porkodi V., Manikandan V., Yuvaraj N. (2019) Advanced Expert System Using Particle Swarm Optimization Based Adaptive Network Based Fuzzy Inference System to Diagnose the Physical Constitution of Human Body. In: Somani A., Ramakrishna S., Chaudhary A., Choudhary C., Agarwal B. (eds) Emerging Technologies in Computer Engineering: Microservices in Big Data Analytics. ICETCE 2019. 
Communications in Computer and Information Science, vol 985. Springer, Singapore

44. Sivaram M. et al. (2019) Expert System in Determining the Quality of Superior Gourami Seed Using Forward Chaining-Based Websites. In: Somani A., Ramakrishna S., Chaudhary A., Choudhary C., Agarwal B. (eds) Emerging Technologies in Computer Engineering: Microservices in Big Data Analytics. ICETCE 2019. Communications in Computer and Information Science, vol 985. Springer, Singapore

45. Amin Salih Mohammed et al., "Analysis of Mobile IP Wireless Networks in 5G International", Journal of Advanced Trends in Computer Science and Engineering, 8(1.2), 2019, 39- 42

46. S. Jeya Shobana et al., " FCCP - NS: A Fair Congestion Control Protocol with N-Sinks in Wireless Sensor Networks", International Journal of Advanced Trends in Computer Science and Engineering, 8(1.2), 2019, 43- 51

47. Sivaram, M., et al. "Retransmission DBTMA Protocol with Fast Retransmission Strategy to Improve the Performance of MANETs." IEEE Access (2019).

48. Yuvaraj D, Sivaram M, Karthikeyan B, and Jihan Abdulazeez, "Shape, Color and Texture Based CBIR System Using Fuzzy Logic Classifier" CMC, vol.59, no.3, pp.729-739, 2019. 